УДК 629.436

DOI 10.47049/2226-1893-2020-2-130-141

\title{
ВИКОРИСТАННЯ В СУДНОВИХ ЕНЕРГЕТИЧНИХ УСТАНОВКАХ ТЕХНОЛОГІЇ ГІДРОДИНАМІЧНОЇ СУПЕРКАВІТАЦІї ДЛЯ РОЗДІЛЕННЯ І ОЧИЩЕННЯ ВОД, ЩО МІСТЯТЬ НАФТУ
}

\author{
I.В. Ткаченко
}

кандидат технічних наук, доцент

Національний університет «Одеська морська академія»

Анотація. Наведено аналіз існуючих даних з проблеми виникнення, зберігання, транспортування та сепаращії вод, що містять нафту морських суден. Розглянуто компонентний стан забруднених нафтою вод як дисперсної системи. Зазначено, щя методи, які забезпечують значення концентрації нафтопродуктів на виході з системи очищення менш ніж 15 млн $^{-1}$, характеризуються складністю своєї технічної реалізації та великими витратами (економічними, енергетичними, матеріальними) на поточне обслуговування. Для розподілу вод, щзо містять нафту запропоновано варіант холодного кипіння рідини за рахунок використання гідромеханічного процесу суперкавітачії всередині робочої камери. Показано, що застосування запропонованого способу очищення вод забезпечують залишкову кониентрачію не більше ніж 5 млн ${ }^{-1}$. Доведено, що розроблена установка для сепарації суднових вод, що містять нафту характеризується малими енергетичними затратами та забезпечується стандартним комплексом робот на технічну експлуатачію, технічне обслугову-вання та ремонт.

Ключові слова: суднова енергетична установка; води, що містять нафту; очищення вод, щзо містять нафту; сепарація; кавітація.

УДК 629.436

DOI 10.47049/2226-1893-2020-2-130-141

\section{ИСПОЛЬЗОВАНИЕ В СУДОВЫХ ЭНЕРГЕТИЧЕСКИХ УСТАНОВКАХ ТЕХНОЛОГИИ ГИДРОДИНАМИЧЕСКОЙ СУПЕРКАВИТАЦИИ ДЛЯ РАЗДЕЛЕНИЯ И ОЧИСТКИ НЕФТЕСОДЕРЖАЩИХ ВОД}

И.В. Ткаченко

кандидат технических наук, доцент

Национальный университет «Одесская морская академия»

Аннотация. Приведен анализ существующих данных по проблеме возникновения, хранения, транспортировки и сепарации нефтесодержащих вод морских судов.

(C) Ткаченко I.B., 2020 
Рассмотрено компонентное состояние нефтесодержащуих вод как дисперсной системы. Указано, что методы, которые обеспечивают значения концентрации нефтепродуктов на выходе из системы очистки менее 15 млн $^{-1}$, характеризуются сложностью своей технической реализации и большими затратами (экономическими, энергетическими, материальными) на текущее обслуживание. Для разделения нефтесодержащчих вод предложен вариант холодного кипения жидкости за счет использования гидромеханического процесса суперкавитации внутри рабочей камеры. Показано, что применение предлагаемого способа очистки нефтесодержащих вод обеспечивают остаточную концентрациию не более 5 млн $^{-1}$. Доказано, что разработанная установка для сепарации судовых нефтесодержащчих вод характеризуется мальми энергетическими затратами и обеспечивается стандартными комплексом работа на техническую эксплуатаџию, техническое обслуживание $и$ ремонт.

Ключевые слова: судовая энергетическая установка, нефтесодержащие водь, очистка нефтесодержащих вод, сепарация, кавитация.

\title{
UDC 629.436
}

DOI 10.47049/2226-1893-2020-2-130-141

\section{USE OF HYDRODYNAMIC SUPERCAVITATION TECHNOLOGY FOR THE SEPARATION AND PURIFICATION OF OIL-CONTAINING WATER IN MARINE POWER PLANTS}

\author{
I. Tkachenko \\ Candidate of Technical Sciences, Associate Professor \\ National University «Odessa Maritime Academy»
}

\begin{abstract}
The analysis of existing data on the problem of the occurrence, storage, transportation and separation of oily waters of marine vessels is presented. The component state of oily water as a dispersed system is considered. It is indicated that all known methods developed for the purification of oily waters that use density stratification and mechanical separation are characterized by a low quality of purification. In connection with these, their use is possible only at the stage of preliminary separation. It is also indicated that methods that provide a concentration of oil products at the outlet of the purification system of less than $15 \mathrm{ppm}$ are characterized by the complexity of their technical implementation and high costs (economic, energy, material) for routine maintenance. For the separation of oil-containing water, the option of cold boiling liquid is proposed due to the use of the hydromechanical process of supercavitation inside the working chamber. The technological scheme of the oil-containing water separator is presented, the principle of which is based on the separation of the water component due to the
\end{abstract}


hydrodynamic process of supercavitation and the creation of a vacuum on the suction line of the pump. To increase the intensity of the cavitation process, forced air supply to the working area is proposed. Experimentally determined the optimal (height of the oily layer of liquid) the location of the cavitator and the air distributor. An optimal cavitator shape has been developed, the coordinate characteristics of the passage channel. It is proved that an increase in the diameter at the cut of the cavitator nozzle should occur from the middle of the working chamber towards its edges. It is shown that the application of the proposed method for the purification of oily waters provides a residual concentration of not more than $5 \mathrm{ppm}$. It is proved that the developed installation for the separation of ship oil-containing water is characterized by low energy costs and provides a standard set of work for technical operation, maintenance and repair.

Keywords: sea vessel, oily water, cleaning of oily waters, separation, cavitation.

Постановка проблеми в загальному вигляді. На даний час під час експлуатації всіх типів суден постає проблема виникнення, збору, зберігання і подальшої переробки вод, що містять нафту (ВМН) [1]. Сепарація таких вод, до складу яких в основному входять невикористані в теплових двигунах (дизелях, котлах і турбінах) важкі фракції палива i мастила, $є$ складним технологічним завданням [2]. Відносно морських суден слід зазначити, що ВМН в основному виникають при забезпеченні процесів підготовки та подачі палива, а також мащення та охолодження теплових двигунів, а для суден, що транспортують нафту або продукти нафтохімії, ще й під час миття вантажних танків [3].

Аналіз останніх досліджень і публікацій. Усі відомі методи, які розроблені для очищення ВМН та які використовують густинну стратифікацію і механічне розділення, характеризуються невисокою якістю очищення і можуть застосовуватися тільки на стадії попередньої сепарації [4]. 3 іншого боку, методи, які забезпечують значення концентрації нафтопродуктів на виході з системи очищення менше 15 мг/л, характеризуються одним загальним недоліком - складністю своєї технічної реалізації і великими витратами (економічними, енергетичними, матеріальними) на поточне обслуговування [5].

Постановка завдання. Таким чином, незважаючи на велику кількість досліджень та технологічних рішень, що забезпечують очищення ВMH, існує нерозв'язана проблема - відсутність метода очищення, за допомогою якого можливо забезпечити остаточну концентрацію нафтопродуктів менш ніж 15 мг/л при одночасній мінімальній витраті енергії на цю технологічну операцію. 
Виклад основного матеріалу дослідження. Типовими складовими суднових ВМН є нафта і іï важкі компоненти [6]. У загальному випадку вони являють собою розчин високомолекулярних сполук у низькомолекулярних. У суміші з водою вони $є$ звичайною дисперсною системою [7].

На процес розподілу суднових ВМН у статичному режимі на складові впливає багато чинників - концентрація, розміри частинок, їх механізм взаємодії між собою. У такій дисперсній системі, як суднові ВМН, дисипація енергії, яка спричиняється опором сил в'язкісного походження, зазвичай витрачається за такими трьома напрямками:

- зміна в'язкості, яка проявляється в дисперсному середовищі [8];

- компенсація взаємодії дисперсного середовища, що рухається зі зваженими частинками [9];

- компенсація структурних змін, які спричиняються взаємодією частинок дисперсної фази [6].

Проведений аналіз головних компонент суднових ВМН, їх основних реологічних властивостей, а також методів і пристроїв, що застосовуються для їхнього зберігання, транспортування та переробки, вказав на необхідність розробки принципово нової технології щодо їх відділення від основної водної компоненти. Одним із варіантів подібного підходу може бути використання та управління основними гідромеханічними характеристиками рухомого середовища. У даному випадку передбачається використання ефекту холодного кипіння рідини за умови виникнення гідромеханічного процесу суперкавітації всередині спеціально спрофільованої робочої камери, що $є$ невід'ємною частиною суднової системи сепарації ВМН. Перевага пропонованого гідродинамічного підходу $\epsilon$ перспективною і з економічної точки зору. Енергетичні витрати на гідромеханічне емульгування води 3 нафтопродуктами в 10-15 разів менше, ніж під час використання технології ультразвукової кавітації [4].

Під час проведення експериментів необхідно вивчити характер руху потоку всередині двох каналів, загальна схема яких представлена на рис. 1. Кавітаційна суперкаверна в першому випадку буде утворюватися безпосередньо за гострою кромкою конусу, що виступає. Оптимальний ступінь перекриття потоку в цьому випадку визначається емпіричним шляхом.

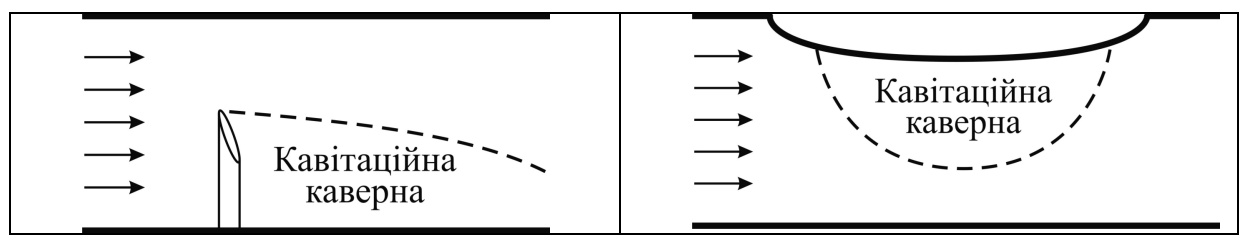

Рис. 1. Форми прохідного перетину кавітатора 
У другому випадку каверна має утворюватися на увігнутій стінці каналу за рахунок локальної зміни градієнта тиску за довжиною. Один із варіантів координатних характеристик верхньої стінки такого каналу показаний на рис. 2. При цьому нормування координат проводилося на радіус вхідного каналу $R$ і половину довжини $l$ увігнутої частини. Поздовжня вісь координат збігається 3 нижньою стінкою, а вертикальна проходить через початок зміни кривизни верхньої стінки.

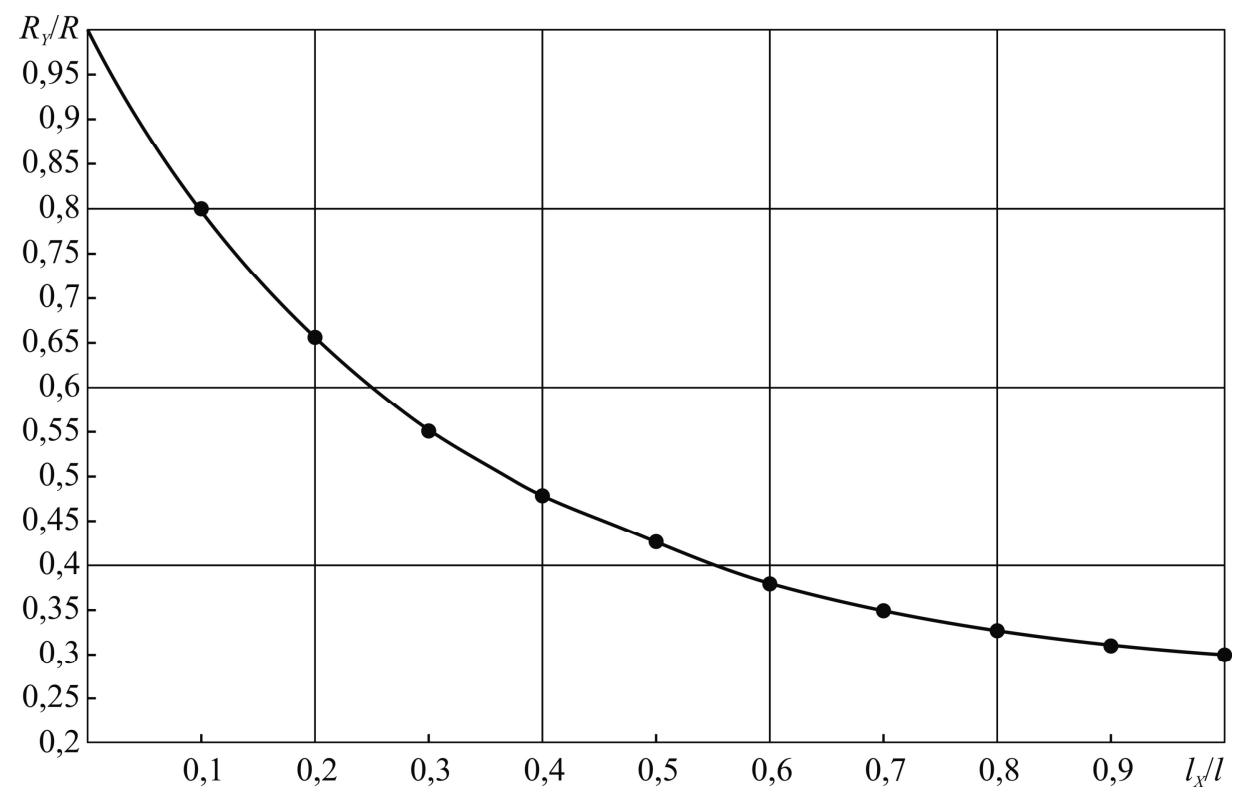

Рис. 2. Координатні характеристики каналу

Колектор вхідний камери перед кавітатором є трубою, обидва кінці якої герметично закриті заглушками, які накручуються з обох боків за допомогою зовнішнього нарізного сполучення. У середній частині труби уварений патрубок, за допомогою якого вона з'єднується з трубопроводом, що подає лляльні води. На трубі є отвори, до кожного з яких приварені втулки, що містять внутрішню різьбу. На кожну втулку (з кроком через втулку) на різьбу накручуються сопла, що створює необхідний початковий динамічний напір.

3 кожного сопла зі швидкістю не менше $15 \mathrm{~m} / \mathrm{c}$, випливають лляльні води, утворюючи струмінь, зовнішня межа якого на деякій відстані від зрізу сопла перетинається з зовнішніми контурами струменів від сусідніх сопел. У підсумку всередині кавітатора утворюється фронт суцільного розмиву. Оскільки сопла розташовуються по всій ширині колектора, ширина фронту суцільного розмиву відповідає ширині кавітатора. 
ВІСНИК

ОДЕСЬКОГО НАЦІОНАЛЬНОГО

МОРСЬКОГО УНІВЕРСИТЕТУ

№ 2 (62), 2020
HERALD

OF THE ODESSA NATIONAL

MARITIME UNIVERSITY № 2 (62), 2020

Для запобігання застійних зон у кутах робочої камери кавітатора по ширині колектора необхідно встановлювати сопла змінного перерізу. Зростання діаметра на зрізі сопла повинно збільшуватися від середини робочої камери до ії країв.

3 метою розв'язання зазначених проблем була розроблена установка, принципова схема якої показана на рис. 3. Принцип іiі роботи заснований на автоматичному контролі і регулюванні основних гідродинамічних характеристик потоку суднових $\mathrm{BMH}$, які циркулюють по замкненому контуру [10].

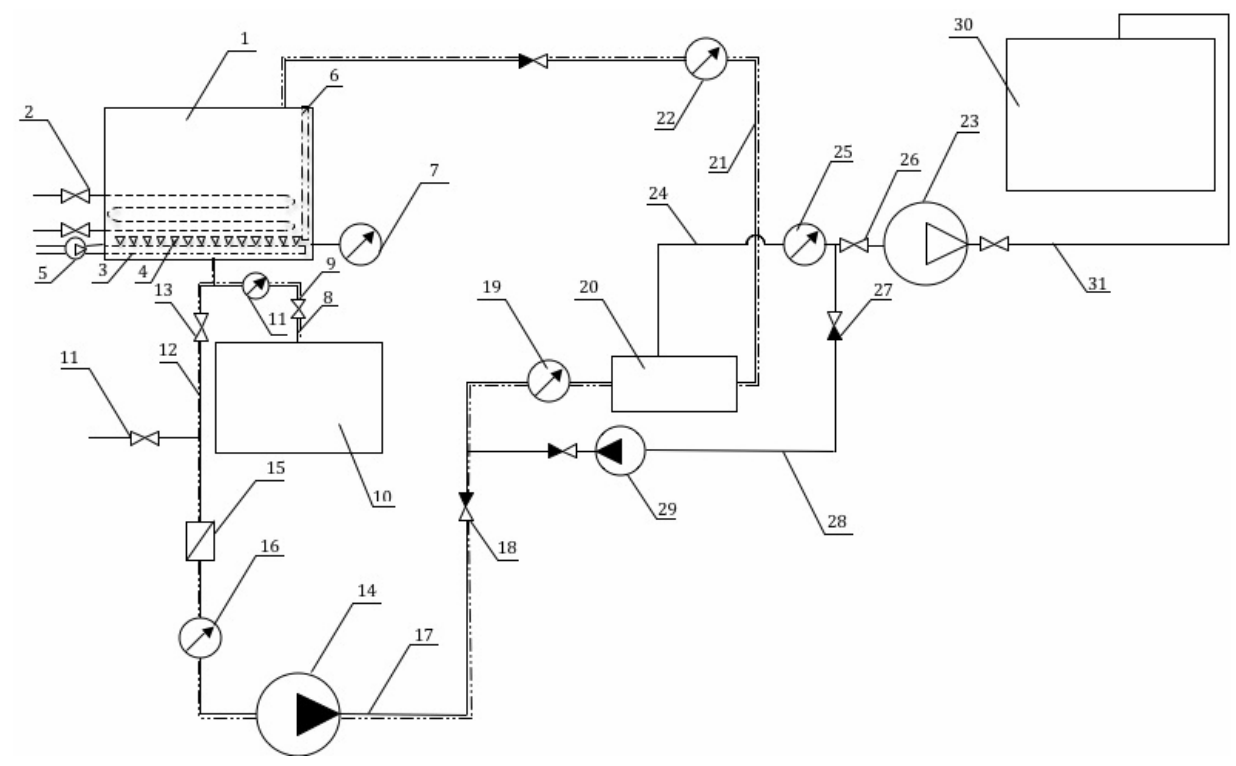

Рис. 3. Принципова схема суднової установки з очищення ВМН:

1 - сервісний танк; 2 - змійовиковий підігрівач;

3 - повітряний трубопровід;

4, 9, 13, 18, 26, 27 -автоматичний клапан; 5, 23 -компресор;

6 - поплавковий рівнемір; 7 - термометр;

8, 17, 21, 24, 28, 31-трубопровід; 10-збірний танк;

11 - вимірювач концентрачії нафти;

12 - лінія основного контуру обробки суднових ВMH;

14 - відиентровий насос; 15 - система фільтраиії (сітка);

16 - вакуумметр; 19 -манометр; 20-кавітатор;

22, 25 - датчик кониентрації; 29 - шестерінчастий насос;

30 - конденсаційний танк 
Установка працює в такий спосіб: до сервісного танка 1 суднові ВМН надходять 3 різних технологічних ділянок судна. До основного переліку таких ділянок відносяться: носові, кормові та центральні колодязі, різні танки для збору залишків палива і мастила, а також танки збору промивної води (у разі її використання на суднах, що перевозять нафтопродукти).

Сервісний танк 1 укомплектований змійовиковим підігрівачем 2. Цей підігрівач служить для розігріву або підтримки на постійному рівні температури суднових вод, що містять нафту. Зазвичай робочий діапазон температури складає $30-80{ }^{\circ} \mathrm{C}$. Підігрів здійснюється з метою проведення попередньої флотації, у результаті якої буде відбуватися густинна стратифікація ВМН. У цьому випадку буде мати місце поділ по висоті танку 1 вихідної суміші на її компоненти - освітлену воду і продукти нафтохімії. 3 метою інтенсифікації процесу попереднього розподілу в танку 1 використовується повітряна завісь, що створюється бульбашками, які рухається 3 прокладеного по дну танка 1 повітряного трубопроводу 3. Для автоматичної підтримки витрати повітря на постійному рівні на трубопроводі 3 встановлена серія автоматичних клапанів 4 .

Під час експлуатації судна завжди має місце випадання твердого осаду 3 суднових ВМН. Зазвичай рівень відкладень у період між очищеннями танка (у середньому від 7 до 9 місяців) може досягати до $10 \%$ від його висоти. 3 цієї причини магістраль подачі повітря 3 встановлюється відносно дна на відстані $14-17$ \% висоти танка. Стисле повітря подається до повітряного трубопроводу 3 за допомогою компресора 5. Для конт-ролю за рівнем наповнення і температурою суднових ВМН у танку 1 використовуються поплавковий рівнемір 6 і термометр 7.

Для відбору світлої води після попереднього процесу флотації на висоті 5-7 \% верхнього рівня танка 1 приєднується трубопровід 8. На ньому встановлюється автоматично керований клапан 9. По лінії 8 світла вода з малою концентрацією нафтопродуктів надходить у збірний танк 10. Для керування клапаном 9 на відвідному трубопроводі 8 встановлений вимірник концентрації нафти 11. При перевищенні встановленого граничного значення концентрації нафтопродуктів цей датчик подає сигнал на закриття клапана 9 і на відкриття встановленого на лінії основного контуру обробки суднових ВМН 12 автоматичного клапана 13.

3 танка 1 суднові ВМН відбираються за допомогою відцентрового насоса 14. На вході в насос встановлена фільтраційна сітка 15 i вакуумметр 16. Фільтраційна сітка 15 призначена для затримання великих забруднювальних речовин і предметів (ганчір'я, папір, металева стружка тощо) і забезпечує безперебійну і тривалу експлуатацію насоса 14. За допомогою показів вакуумметра 16 можна зробити висновки про ступінь забруднення фільтраційної сітки 15 і контролювати вакуум, створюваний насосом 14 на лінії всмоктування. 
На трубопроводі 17, тобто на лінії нагнітання за насосом 14, для керування витратними характеристиками оброблюваного потоку суднових ВМН встановлено автоматично керований вентиль 18. Також за насосом встановлений манометр 19, який в автоматичному режимі надає дані про величину тиску в робочому контурі сепараційної установки. На основному робочому трубопроводі 12 за допомогою фланцевого з'єднання встановлений основний технологічний елемент суднової сепараційної установки - кавітатор 20. Він являє собою спеціально спрофільовану камеру, усередині робочого каналу якої за рахунок локального падіння тиску (локального зростання швидкості) виникає і в подальшому стаціонарно підтримується гідродинамічний процес суперкавітації. Технологічно кавітатор 20 виконаний у вигляді плоского каналу, складається 3 плавно звужуваного сопла, прямолінійного вузької ділянки і плавно розширюваного дифузора. Конструкція кавітатора забезпечує отримання високих швидкостей потоку i зменшення тиску, що $є$ невід'ємною складовою процесу кавітації.

На виході $з$ кавітатора 20 відокремлені продукти, що містять нафту, потрапляють у трубопровід 21. На ньому встановлений блок вимірювання концентрації водної компоненти в продуктах, що містять нафту 22. Трубопроводом 21 суміш надходить назад до сервісного танка 1. Під час роботи установки датчик концентрації 22 показує ступінь очищення суднових ВМН і контролює процес їх відділення. Якщо концентрація водної компоненти не знизилася до заданого рівня, то процес відділення триватиме за описаним замкненим контуром обробки. Циркуляція суднових ВМН повинна підтримуватися доти, доки датчик 22 не покаже заданий ступінь очищення води.

У результаті процесу холодного кипіння, що зумовлюється кавітацією всередині кавітатора, виходить холодна водяна пара. 3 кавітатора 20 вона відбирається за допомогою компресора 23 трубопроводом 24. На лінії всмоктування 24 перед компресором 23 встановлений датчик вимірювання концентрації нафтопродуктів у водяній парі 25. Також на лінії всмоктування встановлений автоматично регульований клапан 26. Управління цього клапана здійснюється від датчика концентрації 25. Якщо концентрація нафтопродуктів у водяних парах перевищує задане значення, то датчик 25 подає сигнал до автоматичного клапану 26 - і він закривається. У цьому випадку водяну пару необхідно піддавати додатковій санітарно-гігієнічній обробці. Отримані продукти нафтохімії зі збірного танка 1 можна також використовувати в енергетичних потребах судна в якості вторинних енергетичних ресурсів.

Для управління всією захисно-регулювальною автоматикою сепараційної установки передбачається установка електронного щита. 
Висновки і перспективи подалыших досліджень. Виконані дослідження дозволяють зробити наступні висновки:

1) розроблений новий метод сепарації дозволяє очищувати суднові води, що містять нафту 3 вихідною концентрацією води на рівні менше 5 млн $^{-1}$, що забезпечує міжнародні вимоги відносно запобігання забрудненню морського середовища 3 суден;

2) нафтопродукти (паливо і моторне мастило), які видаляються 3 суднових вод, що містять нафту розробленим способом суперкавітації, можуть використовуватися як вторинне джерело енергії, яке спрямовується на енергетичні потреби судна (як правило, для роботи суднової котельної установки);

3) розроблена установка для сепарації суднових вод, що містять нафту, характеризується малими енергетичними витратами і забезпечується стандартними витратами на технічну експлуатацію, технічне обслуговування та ремонт.

Подальші розробки методу суперкавітації доцільно спрямувати на розроблення технології поділення та очищення нафто-водяних сумішей при температурі, що не перевищує $30{ }^{\circ} \mathrm{C}$ (тобто безпосередньо 3 ллял машинного відділення). Це буде сприяти зниженню витрат енергії на процес очищення вод, що містять нафту, а також забезпеченню екологічної надійності суднової енергетичної установки [11].

\section{СПИСОК ЛІТЕРАТУРИ}

1. Малахов А.В. Гидродинамическая технология обработки судовых льяльных вод / А.В. Малахов, И.В. Ткаченко, О.Е. Гугуев, А.А. Мусорин // Проблеми техніки: наук.-виробн. журнал. 2009. Odecca. № 3. C. 76-82.

2. Kuropyatnyk, O.A. Exhaust Gas Recirculation as a Major Technique Designed to Reduce NOx Emissions from Marine Diesel Engines / O.A. Kuropyatnyk, S.V.Sagin // OUR SEA : International Journal of Maritime Science \& Technology. 2019. Vol. 66. Iss. 1. P. 1-9.

3. Малахов А.В. Совершенствование эксплуатачионных показателей системы инертных газов на танкерах / А.В. Малахов, М.А. Колегаев, И.Д. Бражник // Вісник Херсонського начіонального технічного університету. 2018. № 2(65). С. 27-34.

4. Мачкевич Д.В. Управление реологическими характеристиками моторных масел судовых дизелей / Д.В. Мачкевич // Проблеми техніки: наук.-виробн. журнал. 2013. № 2. С. 52-60. 
ВІСНИК

ОДЕСЬКОГО НАЦІОНАЛЬНОГО

МОРСЬКОГО УНІВЕРСИТЕТУ

№ 2 (62), 2020
HERALD

OF THE ODESSA NATIONAL

MARITIME UNIVERSITY

№ 2 (62), 2020

5. Ткаченко И.В. Очистка нефтесодержаших вод морских судов методом гидродинамической суперкавитации потока / И.В. Ткаченко // Universum: Технические науки. 2018. Bbin. 3(48). C. 59-62.

6. Поповский А.Ю. Оџенка эксплуатационных свойств смазочноохлаждающих жидкостей судовых технических средств / А.Ю. Поповский, С.В. Сагин // Автоматизачия судовых технических средств: науч.-техн. сб. 2016. Bып. 22. С. 66-74.

7. Сагин С.В. Оптические характеристики граничных смазочных слоев масел, применяемых в ииркулячионных системах судовых дизелей / С.В. Сагин, Д.В. Мачкевич // Судовые энергетические установки: науч.-техн. сб. 2011. № 26. Одесса: OHMA. C.116-125.

8. Сагин С.В. Определение триботехнических характеристик поверхностей по степени упорядоченности пристенных слоев углеводородных жидкостей / С.В. Сагин, Ю.В. Заблочкий // Проблеми техніки: наук.-виробн. журнал, 2011. № 3. Одесса: ОНМУ. С. 78-88.

9. Поповский А.Ю. Комплексная оценка эксплуатационных характеристик смазочных углеводородных жидкостей / А.Ю. Поповский, С.В. Сагин // Автоматизация судовых технических средств: науч.-техн. сб. 2014. Bып. 20. С. 74-83.

10. Ткаченко И.В. Метод отделения водной компоненты от нертесодержащих примесей в судовых льяльных водах, основанный на гидродинамическом проиессе суперкавитации / И.В. Ткаченко // Проблеми техніки: наук.-виробн. журнал. 2010. № 3. C. 59-70.

11. Куропятник А.А. Управление выпускными газами судовых дизелей для обеспечения экологических показателей / А.А. Куропятник, С.В. Сагин // Автоматизация судовых технических средств: науч.-техн. сб., 2018. Bыn. 24. С. 72-80.

\section{REFERENCES}

1. Malakhov, A.V., Tkachenko, I.V., Guguev, O.E., Musorin, A.A. (2009) Gidrodinamicheskaya tehnologiya obrabotki sudovyh lyalnyh vod [Hydrodynamic technology for the treatment of ship bilge water]. Problemy texniky : naukovo-vyrobnychj zhurnal, no. 3, pp. 76-82. 
2. Kuropyatnyk, O.A., Sagin, S.V. (2019). Exhaust Gas Recirculation as a Major Technique Designed to Reduce NOx Emissions from Marine Diesel Engines. OUR SEA : International Journal of Maritime Science \& Technology, vol. 66, no. 1, pp. 1-9. doi.org/ 10.17818/NM/2019/1.1.

3. Malakhov, A.V., Kolegaiev, M.O., Brazhnik, I.D. (2018). Sovershenstvovanie ekspluatacionny pokazatelej sistemy inertnyh gazov na tankerah [Improving the performance of an inert gas system on tankers]. Visnyk Xersonskogo nacionalnogo texnichnogo universytetu, no. 2(65), pp. 27-34.

4. Matskevich, D.V. (2013). Upravlenie reologicheskimi harakteristikami motornyh masel sudovyh dizelej [Management of the rheological characteristics of marine diesel engine oils]. Problemy texniky: naukovo-vyrobnychj zhurnal, no. 2, pp. 52-60.

5. Tkachenko, I.V. (2018). Ochistka neftesoderzhashih vod morskih sudov metodom gidrodinamicheskoj superkavitacii potoka [Purification of oily water in ships by hydrodynamic supercavitation flow]. Universum: Technical science, no. 3(48), pp. 59-62. (in Russian)

6. Popovskii, A.Yu., Sagin, S.V. (2016) Ocenka ekspluatacionnyh svojstv smazochno-ohlazhdayushih zhidkostej sudovyh tehnicheskih sredstv [Evaluation of the operational properties of cutting fluids of marine technical equipment]. Avtomatizaciya sudovyh tehnicheskih sredstv: nauchno-tehnicheskij sbornik, no. 22, pp. 66-74.

7. Sagin, S.V., Matskevich, D.V. (2011). Opticheskie harakteristiki granichnyh smazochnyh sloev masel, primenyaemyh $v$ cirkulyacionnyh sistemah sudovyh dizelej [Optical characteristics of boundary lubricating layers of oils used in marine diesel circulating systems]. Sudovye energeticheskie ustanovki: nauchnotehnicheskij sbornik, no. 26, pp. 116-125.

8. Sagin, S.V., Zablotsky, Yu.V. (2011). Opredelenie tribotehnicheskih harakteristik poverhnostej po stepeni uporyadochennosti pristennyh sloev uglevodorodnyh zhidkostej [Determination of tribolo-gical characteristics of surfaces according to the degree of ordering of wall layers of hydrocarbon fluids]. Problemy texniky: naukovo-vyrobnychj zhurnal, no. 3, pp. 78-88.

9. Popovskii, A.Yu., Sagin, S.V. (2014). Kompleksnaya ocenka ekspluatacionnyh harakteristik smazochnyh uglevodorodnyh zhidkostej [Comprehensive performance assessment of lubricating hydrocarbon fluids]. Avtomatizaciya sudovyh tehnicheskih sredstv: nauchno-tehnicheskij sbornik, no. 20, pp. 74-83. 
ВІСНИК

ОДЕСЬКОГО НАЦІОНАЛЬНОГО

МОРСЬКОГО УНІВЕРСИТЕТУ

№ 2 (62), 2020
HERALD

OF THE ODESSA NATIONAL

MARITIME UNIVERSITY

№ 2 (62), 2020

10. Tkachenko, I.V. (2010). Metod otdeleniya vodnoj komponenty ot neftesoderzhashih primesej $v$ sudovyh lyalnyh vodah, osnovannyj na gidrodinamicheskom processe superkavitacii [The method of separation of the aqueous component from oil-containing impurities in ship's bilge waters, based on the hydrodynamic process of supercavitation]. Problemy texniky: naukovo-vyrobnychj zhurnal, no. 3, pp. 59-70.

11. Kuropyatnyk, O.A., Sagin, S.V. (2018). Upravlenie vypusknymi gazami sudovyh dizelej dlya obespecheniya ekologicheskih pokazatelej [Controlling the exhaust gases of marine diesel engines to ensure environmental performance]. Avtomatizaciya sudovyh tehnicheskih sredstv: nauchno-tehnicheskij sbornik, no. 24, pp. 72-80.

Стаття надійшла до редакиії 24.01.2020

Посилання на статтю: Ткаченко І.В. Використання в суднових енергетичних установках технології гідродинамічної суперкавітації для розділення і очищення вод, що містять нафту // Вісник Одеського національного морського університету: Зб. наук. праць, 2020. № 2(62). С. 130-141. DOI 10.47049/2226-1893-2020-2-130-141.

Article received 24.01.2020

Reference a JournalArtic: Tkachenko I. Use of hydrodynamic supercavitation technology for the separation and purification of oil-containing water in marine power plants // Herald of the Odessa national maritime university. 2020. 2(62), 130-141. DOI 10.47049/2226-1893-2020-2-130-141. 